\title{
Dental pulp stem cell responses to novel antibiotic-containing scaffolds for regenerative endodontics
}

\author{
K. Kamocki ${ }^{1}$, J. E. Nör² \& M. C. Bottino ${ }^{1}$ \\ ${ }^{1}$ Department of Restorative Dentistry, Division of Dental Biomaterials, Indiana University School of Dentistry (IUSD), \\ Indianapolis, IN; and ${ }^{2}$ Department of Cariology, Restorative Sciences and Endodontics, University of Michigan School of \\ Dentistry, Ann Arbor, MI, USA
}

\begin{abstract}
Kamocki K, Nör JE, Bottino MC. Dental pulp stem cell responses to novel antibiotic-containing scaffolds for regenerative endodontics. International Endodontic Journal, 48, 1147-1156, 2015.
\end{abstract}

Aim To evaluate both the drug-release profile and the effects on human dental pulp stem cells' (hDPSC) proliferation and viability of novel bi-mix antibioticcontaining scaffolds intended for use as a drug delivery system for root canal disinfection prior to regenerative endodontics.

Methodology Polydioxanone (PDS)-based fibrous scaffolds containing both metronidazole (MET) and ciprofloxacin (CIP) at selected ratios were synthesized via electrospinning. Fibre diameter was evaluated based on scanning electron microscopy (SEM) images. Pure PDS scaffolds and a saturated CIP/MET solution (i.e. $50 \mathrm{mg}$ of each antibiotic in $1 \mathrm{~mL}$ ) (hereafter referred to as DAP) served as both negative (nontoxic) and positive (toxic) controls, respectively. High-performance liquid chromatography (HPLC) was performed to investigate the amount of $\operatorname{drug}(\mathrm{s})$ released from the scaffolds. WST- $1^{\circledR}$ proliferation assay was used to evaluate the effect of the scaffolds on cell proliferation. LIVE/DEAD ${ }^{\circledR}$ assay was used to qualitatively assess cell viability. Data obtained from drug release and proliferation assays were statistically analysed at the 5\% significance level.

Results A burst release of CIP and MET was noted within the first $24 \mathrm{~h}$, followed by a sustained maintenance of the $\operatorname{drug}(\mathrm{s})$ concentration for 14 days. A concentration-dependent trend was noticed upon hDPSCs' exposure to all CIP-containing scaffolds, where increasing the CIP concentration resulted in reduced cell proliferation $(P<0.05)$ and viability. In groups exposed to pure MET or pure PDS scaffolds, no changes in proliferation were observed.

Conclusions Synthesized antibiotic-containing scaffolds had significantly lower effects on hDPSCs proliferation when compared to the saturated CIP/MET solution (DAP).

Keywords: antibiotic pastes, drug delivery, nanofibres, regeneration, root canal, stem cells.

Received 16 May 2014; accepted 20 November 2014

\section{Introduction}

Treatment of pulpal necrosis of immature permanent teeth is challenging due to its uncertain prognosis

Correspondence: Dr. Marco Cicero Bottino, Indiana University School of Dentistry, Department of Restorative Dentistry, Division of Dental Biomaterials, $1121 \mathrm{~W}$. Michigan St. (DS112A), Indianapolis, IN, 46202 USA (Tel.: +1-317-2743725; Fax: +1-317-278-7462; e-mail: mbottino@iu.edu).
(Andreasen et al. 2002, Ribeiro et al. 2008). Recently, regenerative endodontics has become a rational alternative to classical root apexification (Banchs \& Trope 2004). It relies on copious chemical canal irrigation with minimal or no mechanical root canal preparation, followed by the application of a mixture of antibiotics for nearly 1 month (Banchs \& Trope 2004, Geisler 2012). During the next visit, canal contents are removed via irrigation, and bleeding from periapical tissue is prompted (Murray et al. 2007). The evoked bleeding leads to the accumulation of 
undifferentiated stem cells (Lovelace et al. 2011), which, according to the literature, can play an important role in the regeneration of pulpal tissues (Murray et al. 2007, Diogenes et al. 2014). Overall, this innovative endodontic procedure has led, according to clinical cases and case series, to increased root length, apical closure and continuing thickness of dentine walls, amongst other positive clinical findings (Banchs \& Trope 2004, Kim et al. 2010, Petrino et al. 2010, Lin et al. 2013, Simon \& Smith 2014).

One of the most critical steps in regenerative endodontics is the complete eradication of residual infection (Albuquerque et al. 2014). Typically, this is achieved by the application of calcium hydroxide. As an alternative, triple antibiotic paste (TAP) containing CIP, MET, and minocycline or double antibiotic paste (DAP), containing CIP and MET, are used (Hoshino et al. 1996, Sato et al. 1996). Notably, the use of both calcium hydroxide and antibiotic pastes has demonstrated several important side effects. The former has been associated with root weakening when used for both short (Sahebi et al. 2010, Yassen et al. 2013) and long (Andreasen et al. 1989, Yassen et al. 2013, Moazami et al. 2014) periods of time. On the other hand, the use of clinically recommended dosages of TAP and DAP pastes has led to unfavourable effects on dental pulp cells (Ruparel et al. 2012, Chuensombat et al. 2013), as well as periodontal ligament fibroblasts (Yadlapati et al. 2014), posing important questions towards the predictability of regenerative procedures. Moreover, current irrigation methods do not completely remove the remnants of antibiotic pastes from root canals (Berkhoff et al. 2014).

In the light of this, drug delivery-based strategies, to reduce the local drug concentration through the use of antibiotic-containing nanofibres, have been proposed recently (Bottino et al. 2011, 2013a, 2014, Albuquerque et al. 2014, Palasuk et al. 2014, Waeiss et al. 2014). Therefore, the hypotheses of the study were that the amount of $\operatorname{drug}(\mathrm{s})$ released from these novel antibiotic-containing scaffolds (i) would lead to reduced cell toxicity, and more importantly (ii), it would diminish the negative impact on hDPSC proliferation when compared to the double antibiotic (DAP) paste (i.e. ciprofloxacin and metronidazole mixture).

\section{Materials and methods}

\section{Fabrication of the antibiotic-containing scaffolds}

The synthesis of antibiotic-containing nanofibrous scaffolds has been described in detail (Bottino et al.
2011, 2013a, 2014, Palasuk et al. 2014, Waeiss et al. 2014). Briefly, MET (Sigma-Aldrich, St. Louis, MO, USA), and CIP (Sigma-Aldrich) bi-mix polydioxanonebased (PDS II ${ }^{\circledR}$, Ethicon, Somerville, NJ, USA) solutions were prepared to obtain distinct MET/CIP-containing scaffolds. Pure MET and CIP scaffolds were also prepared. PDS pieces were dissolved in 1,1,1,3,3,3-hexafluoro-2-propanol (HFP, Sigma-Aldrich). MET and CIP were added alone and in different ratios (by weight, wt.\%) into the PDS solutions and mixed overnight (Bottino et al. 2013a, Palasuk et al. 2014). The following groups of scaffolds were prepared: pure MET, pure CIP, 3:1MET/CIP, 1:1MET/CIP and 1:3MET/CIP (Palasuk et al. 2014). All antibiotic-containing PDS solutions were incorporated with $25 \mathrm{wt}$. $\%$ of antibiotic (s) in total relative to the PDS polymer weight (i.e. $150 \mathrm{mg}$ of $\operatorname{drug}(\mathrm{s})$ in total) (Bottino et al. 2013a). Pure PDS scaffolds and a saturated CIP/MET solution (i.e. $50 \mathrm{mg}$ of each antibiotic in $1 \mathrm{~mL}$ ) (DAP) (Sabrah et al. 2013) served as negative (nontoxic) and positive (toxic) controls, respectively. Antibiotic-containing solutions and pure PDS were loaded into 5-mL syringes (Becton-Dickinson, Franklin Lakes, NJ, USA) fitted with $27 \mathrm{G}$ metallic blunt-tip needles. Electrospinning was conducted at $2 \mathrm{~mL} \mathrm{~h}^{-1}$, from a distance of $18 \mathrm{~cm}$ and by applying electrical voltage between $15-18 \mathrm{kV}$. The scaffolds were processed at room temperature (RT) and then dried for at least $48 \mathrm{~h}$ (Bottino et al. 2013a). Scanning electron microscopy (SEM, JSM-5310LV, JEOL, Tokyo, Japan) was used to evaluate the morphological aspect of the synthesized scaffolds (Bottino et al. 2013a).

\section{Drug release}

Four scaffolds $\left(15 \times 15 \mathrm{~mm}^{2}\right)$ per group were initially weighed and incubated in $10 \mathrm{~mL}$ of phosphate-buffered saline (PBS, pH 7.4, Fisher Scientific, Pittsburgh, PA, USA) and kept in an incubator at $37^{\circ} \mathrm{C}$. Aliquots $(1 \mathrm{~mL})$ of each sample were collected at different time-points (1, 2, 5, 7 and 14 days). Equal amounts of fresh PBS were added back to the incubation media subsequent to each aliquot retrieval (Bottino et al. 2013a). HPLC-UV analysis was performed on an Agilent 1100 system (Palo Alto, CA, USA), using a Zorbax SB-phenyl chromatography column $(5 \mu \mathrm{m}, 150 \times 4.6 \mathrm{~mm}$ i.d $)$ with a $10-\mu \mathrm{L}$ injection volume. A binary mobile phase consisting of solvent systems A and B were used in gradient elution where A was $0.1 \%$ formic acid $(\mathrm{v} / \mathrm{v})$ in $\mathrm{ddH}_{2} \mathrm{O}$ and $\mathrm{B}$ was $0.1 \%$ formic acid $(\mathrm{v} / \mathrm{v})$ in acetonitrile. The 
mobile phase flow rate was $1.0 \mathrm{~mL} \mathrm{~min}^{-1}$. Initial conditions were set at $95: 5 \mathrm{~A}: \mathrm{B}$, followed by a linear gradient to $40: 60$ from 0 to $15 \mathrm{~min}$. Gradient conditions were re-equilibrated to $95: 5$ A:B from 15 to $16 \mathrm{~min}$ and held for $8 \mathrm{~min}$ at initial conditions until $23 \mathrm{~min}$. Following separation, the column effluent was introduced into a UV-Vis photodiode array detector (Agilent). Quantitation wavelengths were $319 \mathrm{~nm}$ for MET and $278 \mathrm{~nm}$ for CIP. Retention times for MET and CIP were $5.4 \mathrm{~min}$ and $7.8 \mathrm{~min}$, respectively. Standard curves for MET and CIP were generated using authentic standards, over a concentration range of $7-280 \mu \mathrm{g} \mathrm{mL}^{-1}$, and then, the drug concentration in the aliquots was calculated. Drugrelease data are shown as the mean value plus or minus the standard deviation $( \pm \mathrm{SD})$ of the mean. The percentage of the released drugs was then calculated based on the initial weight of the drug incorporated into the electrospun scaffolds (Bottino et al. 2013a).

\section{Exposure of hDPSC to antibiotic-containing scaffolds}

Low glucose Dulbecco's Modified Eagle's Medium (DMEM, Gibco, Grand Island, NY, USA), supplemented with $10 \%$ fetal bovine serum (FBS, Hyclone, Logan, UT, USA) and 1\% penicillin-streptomycin (Sigma-Aldrich) in a humidified incubator at $37{ }^{\circ} \mathrm{C}$, with $5 \% \mathrm{CO}_{2}$, was used to culture hDPSC (catalogue number - DP003F, AllCells LLC, Alameda, CA, USA) obtained from permanent third molars. The medium was changed every 2-3 days, and cells at passages 4-6 were used.

Electrospun samples $\left(15 \times 15 \mathrm{~mm}^{2}, n=4\right.$ /group $)$ cut from the distinct antibiotic-containing scaffolds and the control (pure PDS) were mounted in a plastic device (CellCrown ${ }^{\mathrm{TM}}$, Scaffdex, Tampere, Finland), disinfected in $70 \%$ ethanol for $30 \mathrm{~min}$ and rinsed twice in sterile phosphate buffer saline (PBS, Sigma-Aldrich). Meanwhile, hDPSCs were harvested by trypsinization, counted and seeded in 24-well plates at a density of $10^{4} /$ well (in $1500 \mu \mathrm{L}$ of culture medium) on cell culture coverslips (Thermo Scientific Nunc, Rochester, NY, USA). After a 4-h incubation period to allow the cells to be attached, the plastic crowns with scaffolds were introduced into the wells. For standardization purposes, the crowns were separated from the bottom of the plate by a 2-mm distance achieved using plastic rings. Control (blank) columns were prepared with medium without cells and medium with cells but without any scaffolds (100\% survival). In all the controls, for quality purposes, the crowns without scaffolds were introduced. As previously explained, a saturated solution of MET and CIP in complete culture media was used as an equivalent of the DAP (toxic control). The antibiotics were mixed at a concentration of $50 \mathrm{mg} \mathrm{mL}^{-1}$ of each antibiotic (Sabrah et al. 2013). Then, the solution was stirred for $4 \mathrm{~h}$ at RT, centrifuged at $1425 \boldsymbol{g}$ for $15 \mathrm{~min}$, and supernatant was filter-sterilized with a $0.22-\mu \mathrm{m}$ syringe filter.

\section{Evaluation of hDPSCs proliferation and viability}

To assess the effects of antibiotic-containing scaffolds on hDPSC proliferation, the WST-1 assay (Roche Diagnostics, Mannheim, Germany) was used according to the manufacturer's protocol. Briefly, after 3, 5 and 7 days, the CellCrowns ${ }^{\mathrm{TM}}$ were removed and $500 \mu \mathrm{L}$ of culture media was left in the wells, following the addition of WST-1 reagent at the ratio of $10: 1$. After $2 \mathrm{~h}$ of incubation in $5 \% \mathrm{CO}_{2}$ in a humidified atmosphere at $37^{\circ} \mathrm{C}$, the samples were transferred $(100 \mu \mathrm{L})$ into 96 well plates. Full media with cells without exposure to scaffolds was assigned as the positive control, and full media without cells was used as the negative control. The optical density (OD) of the incorporated dye was measured by reading the absorbance at $450 \mathrm{~nm}$ in a microplate reader against a blank column (Allam et al. 2011, Bottino et al. 2013b). Cell proliferation was calculated as a ratio of OD from experimental value to positive control, both subtracted by negative control (Allam et al. 2011, Bottino et al. 2013b).

LIVE/DEAD ${ }^{\circledR}$ assay (Molecular Probes, Invitrogen, Eugene, OR, USA) was used to assess the effects of antibiotic-containing scaffolds on hDPSC viability (Kim et al. 2013). Five samples for each experimental group were analysed at day 3 of exposure according to the manufacturer's instructions. To obtain a negative control, cells were treated with $70 \%$ methanol for $30 \mathrm{~min}$ and cells with no treatment were prepared as a positive control. In brief, LIVE/DEAD ${ }^{\circledR}$ assay uses calcein and ethidium homodimer (EthD-1). Calcein is converted into green product by intracellular esterase, which is active only in viable cells. By contrast, EthD-1, a red staining, has an affinity to nuclei. Nonetheless, to enter the nucleus, the cell membrane must be disrupted. As a result, EthD-1 is detected only in dead cells. Excitation and emission values for calcein and EthD-1 are 494/517 nm and 528/617 nm, respectively. Briefly, after warming LIVE/DEAD ${ }^{\circledR}$ reagent stock solutions to $\mathrm{RT}, 20 \mu \mathrm{L}$ of $2 \mathrm{~m} \mathrm{~mol} \mathrm{~L} \mathrm{~L}^{-1}$ EthD-1 was mixed with $10 \mathrm{~mL}$ of sterile PBS to obtain 
a $4 \mu \mathrm{mol} \mathrm{L}^{-1}$ EthD-1 solution. Next, $5 \mu \mathrm{L}$ of the component A (4 m mol L ${ }^{-1}$ calcein stock solution) was added to the $10 \mathrm{~mL}$ of $4 \mu \mathrm{mol} \mathrm{L}{ }^{-1}$ EthD-1 solution, yielding a $2 \mu \mathrm{mol} \mathrm{L}^{-1}$ calcein $\mathrm{AM}$ solution. $100 \mu \mathrm{L}$ of the LIVE/DEAD ${ }^{\circledR}$ working solution was added to each well, followed by incubation at RT for $30 \mathrm{~min}$. Immediately after all staining procedures (in the dark room), the cells were evaluated directly in the 24-well plates using an inverted fluorescence microscope (Leica DMI 4000B, Wetzlar, Germany) at $25 \times$ magnification with filters 480/527 and 546/ 600 for excitation/emission, respectively. At least six pictures per group were acquired and analysed using Image-J software (NIH, Bethesda, MD, USA).

\section{Statistical analysis}

Drug-release data were analysed by the Student's $t$-test. Data obtained from proliferation were analysed by one-way Anova. Tukey's post hoc test was used to compare differences amongst the groups at the same timepoint. The level of significance was set at $\alpha=0.05$.

\section{Results}

\section{Fibre morphology and drug release}

Scanning electron microscopy (SEM) was used to examine the effect of drug(s) (MET, CIP and MET/CIP mixtures) incorporation on the fibre morphology of the various antibiotic-containing scaffolds synthesized via electrospinning. The results showed a submicron fibre diameter for all electrospun scaffolds. More importantly, fibres of the antibiotic-containing scaffolds had a visibly smaller mean fibre diameter than pure PDS (Fig. 1).

Drug-release profiles from each group of antibioticcontaining scaffolds were examined using HPLC. The
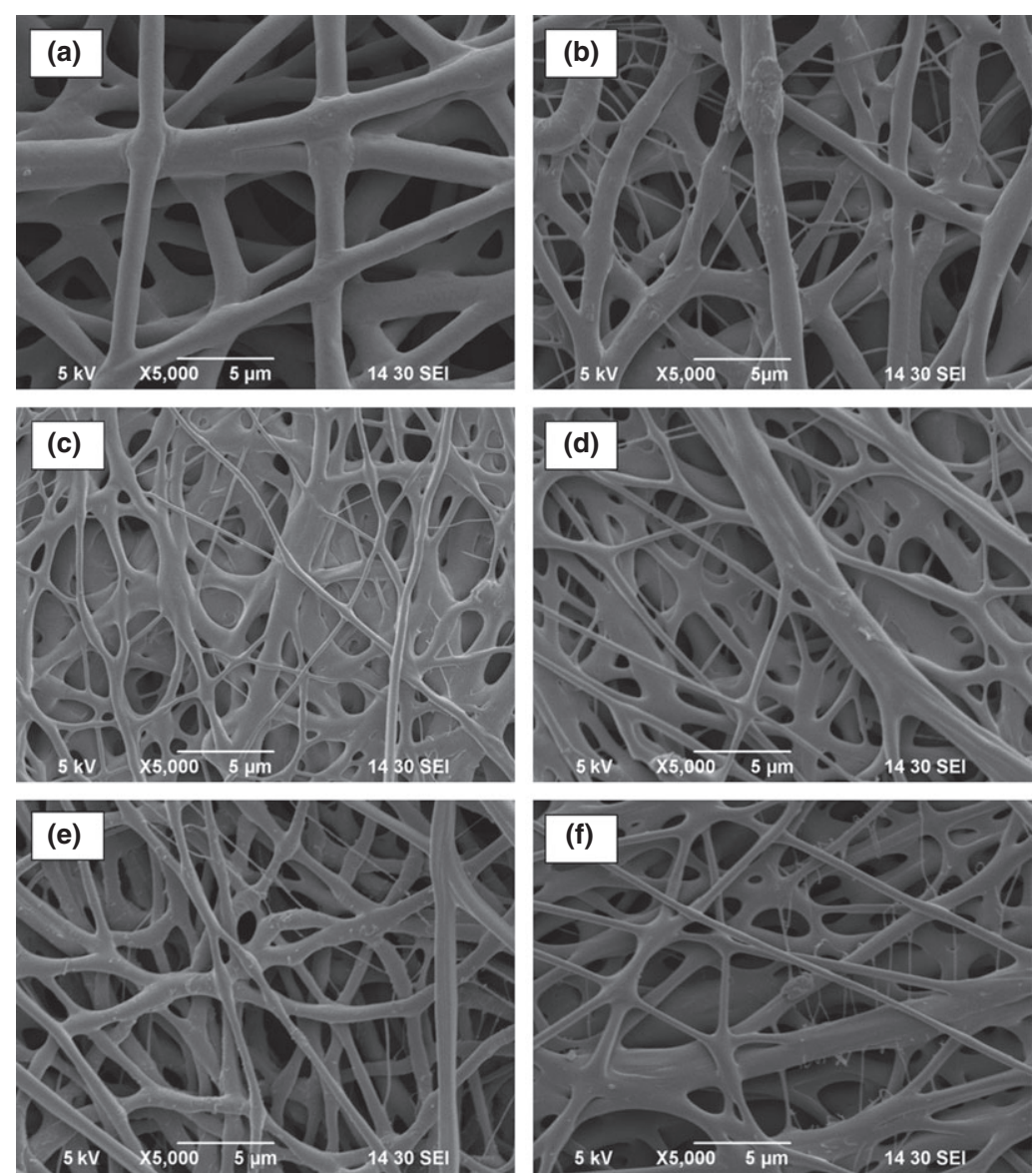

Figure 1 (a-f) Representative SEM images of the electrospun antibiotic-containing scaffolds $(5000 \times$ magnification): (a) Pure PDS, (b) Pure MET, (c) $3: 1 \mathrm{MET} / \mathrm{CIP}$, (d) $1: 1 \mathrm{MET} / \mathrm{CIP}$, (e) $1: 3 \mathrm{MET} / \mathrm{CIP}$ and (f) Pure CIP. 
mean drug release, as well as the percentage (\%) of drug release, was assessed up to 2 weeks as an initial screening of the potential ability of these scaffolds to function as drug delivery systems. A burst drug(s) release was noted within the first $24 \mathrm{~h}$ in all samples. The initial burst release was followed by an overall linear and sustained maintenance of the $\operatorname{drug}(\mathrm{s})$ concentration in the incubation media throughout the 14 days (Fig. 2). The mean MET drug released after 14 days for pure MET, $3: 1 \mathrm{MET} / \mathrm{CIP}, 1: 1 \mathrm{MET} / \mathrm{CIP}$ and $1: 3 \quad$ MET/CIP were $1870 \pm 663.1 \mu \mathrm{g}$, $1260 \pm 229 \mu \mathrm{g}, \quad 1068 \pm 305.9 \mu \mathrm{g}$ and $536 \pm$ $71.6 \mu \mathrm{g}$, respectively (Fig. 2a). Meanwhile, the percentage (\%) of MET drug released after 14 days was
63\% (3: $1 \mathrm{MET} / \mathrm{CIP}$ ), 69\% (pure MET) and 93\% for the $1: 1 \mathrm{MET} / \mathrm{CIP}$ scaffolds (Fig. 2b). 1 : $1 \mathrm{MET} / \mathrm{CIP}$ scaffolds released all MET content by day 5 (Fig. 2b). The mean CIP drug released after 14 days for pure CIP, $3: 1 \mathrm{MET} / \mathrm{CIP}, 1: 1 \mathrm{MET} / \mathrm{CIP}$ and $1: 3 \mathrm{MET} /$ CIP were $966 \pm 166.6 \mu \mathrm{g}, 418 \pm 96.8 \mu \mathrm{g}, 674 \pm$ $105 \mu \mathrm{g}$ and $900 \pm 96.8 \mu \mathrm{g}$, respectively (Fig. 2c). After 14 days, the percentage (\%) of CIP drug released ranged from $32 \%$ for pure CIP to $63 \%$ for 3 : $1 \mathrm{MET} / \mathrm{CIP}$ scaffolds (Fig. 2d). No statistical differences in mean CIP release between pure CIP and $1: 3 \mathrm{MET} / \mathrm{CIP}$ scaffolds (Fig. 2b) were observed. The percentage of CIP drug release was significantly lower $(P<0.05)$ in pure CIP when compared (a)

\begin{tabular}{|l|c|c|c|c|c|}
\cline { 2 - 6 } \multicolumn{1}{c|}{} & Day & MET & $3: 1 \mathrm{MET} / \mathrm{CIP}$ & $1: 1 \mathrm{MET} / \mathrm{CIP}$ & $1: 3 \mathrm{MET} / \mathrm{CIP}$ \\
\hline & 1 & 596.1 & 226.9 & 290.3 & 6.2 \\
\hline Pure MET & 2 & 605.6 & 219.5 & 292.9 & 1.6 \\
\cline { 2 - 6 } \multicolumn{1}{c|}{ 3:1 MET/CIP } & 5 & 605.9 & 212.1 & 324.2 & 8.4 \\
\hline $1: 1 \mathrm{MET} / \mathrm{CIP}$ & 7 & 630.8 & 212.3 & 319.5 & 72.8 \\
\hline $1: 3 \mathrm{MET} / \mathrm{CIP}$ & 14 & 663.1 & 229.1 & 305.9 & 71.6 \\
\hline
\end{tabular}

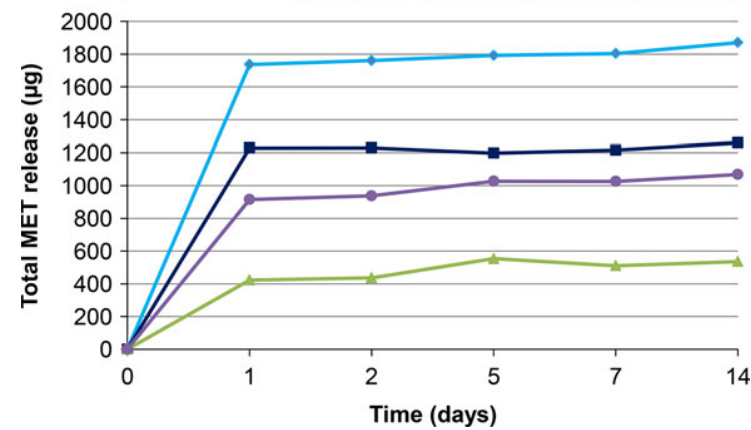

(c)

\begin{tabular}{|c|c|c|c|c|c|}
\hline & Day & CIP & 3:1MET/CIP & 1:1MET/CIP & 1:3MET/CIP \\
\hline \multirow{5}{*}{$\begin{array}{l}\text { 1:3 MET/CIP } \\
\text { Pure CIP } \\
1: 1 \mathrm{MET} / \mathrm{CIP} \\
3: 1 \mathrm{MET} / \mathrm{CIP}\end{array}$} & 1 & 58.2 & 8.7 & 163.8 & 8.7 \\
\hline & 2 & 41.7 & 20.2 & 156.8 & 20.2 \\
\hline & 5 & 73.4 & 108.4 & 175.2 & 108.4 \\
\hline & 7 & 86.0 & 29.1 & 197.8 & 29.1 \\
\hline & 14 & 166.6 & 96.8 & 105.0 & 96.8 \\
\hline
\end{tabular}

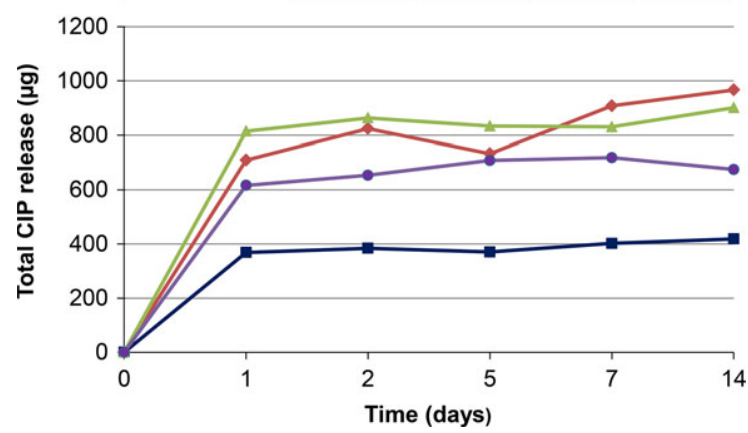

(b)

\begin{tabular}{|c|c|c|c|c|c|}
\cline { 2 - 6 } \multicolumn{1}{c|}{} & Day & MET & $3: 1 \mathrm{MET} / \mathrm{CIP}$ & $1: 1 \mathrm{MET} / \mathrm{CIP}$ & $1: 3 \mathrm{MET} / \mathrm{CIP}$ \\
\cline { 2 - 6 } \multicolumn{1}{c|}{} & 1 & 2.9 & 3.5 & 6.3 & 10.2 \\
\hline $1: 1 \mathrm{MET} / \mathrm{CIP}$ & 2 & 2.5 & 2.0 & 5.9 & 34.2 \\
\hline 3:1 MET/CIP & 5 & 3.3 & 0.8 & 7.0 & 34.8 \\
\hline $1: 3 \mathrm{MET} / \mathrm{CIP}$ & 7 & 3.2 & 1.0 & 6.5 & 45.5 \\
\hline & 14 & 2.8 & 1.9 & 4.0 & 34.2 \\
\hline
\end{tabular}

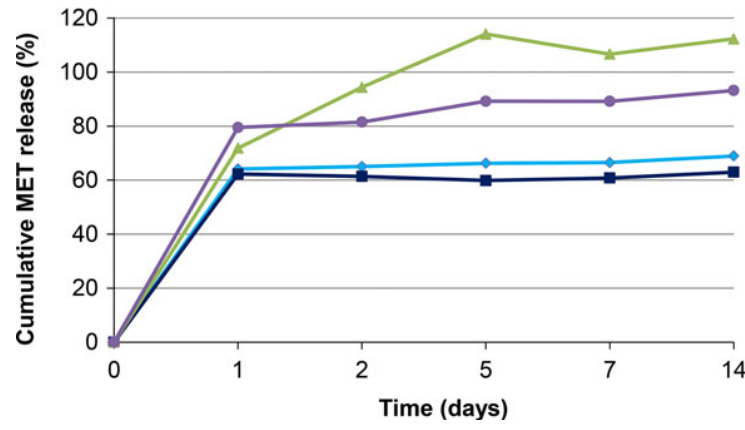

(d)

\begin{tabular}{|c|c|c|c|c|}
\hline Day & CIP & $3: 1$ MET/CIP & $1: 1$ MET/CIP & $1: 3$ MET/CIP \\
\hline 1 & 2.2 & 0.8 & 4.8 & 5.7 \\
\hline 2 & 2.3 & 1.6 & 1.4 & 7.4 \\
\hline 5 & 2.4 & 3.9 & 1.7 & 4.9 \\
\hline 7 & 2.2 & 1.6 & 3.8 & 5.4 \\
\hline 14 & 5.9 & 1.9 & 8.9 & 4.2 \\
\hline
\end{tabular}

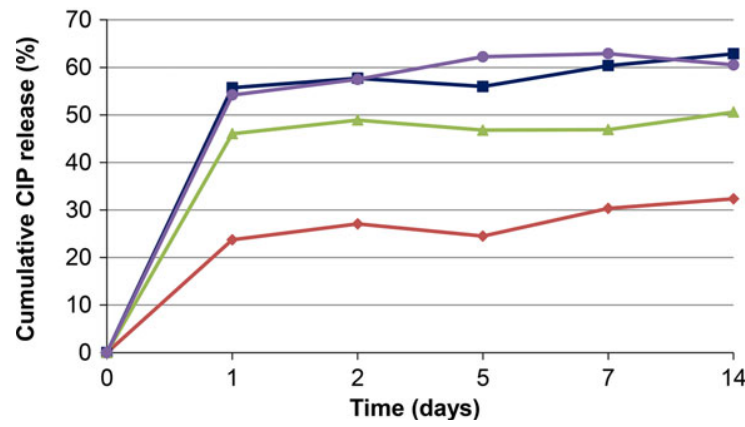

Figure 2 (a-d) Graphs represent both MET and CIP drug release for all antibiotic-containing scaffolds. (a) Mean MET drug release (in $\mu \mathrm{g}, \pm \mathrm{SD}$, refer to inset Table). (b) Percentage of MET drug release ( \pm SD, refer to inset Table) from the scaffolds based on initial weight. (c) Mean CIP drug release (in $\mu \mathrm{g}, \pm \mathrm{SD}$, refer to inset Table). (d) Percentage of CIP drug release ( \pm SD, refer to inset Table) from the scaffolds based on initial weight. 


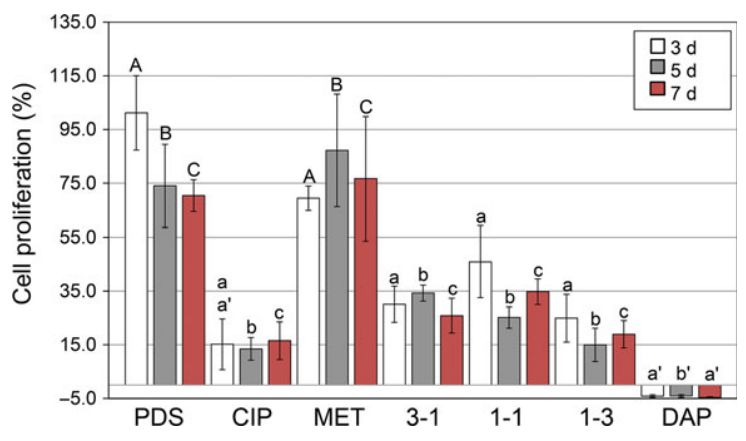

Figure 3 Effects of pure PDS, antibiotic-containing scaffolds and DAP on hDPSCs proliferation. Proliferation was assessed via WST-1 assay after 3, 5 and 7 days of hDPSC exposure to the scaffolds and DAP solution. Data were plotted with mean $( \pm \mathrm{SD})$. Statistical analyses were compared within the results from the same day. Correlation of upper case letter versus lower case letter versus lower case letter with apostrophe denotes statistical significance at the level of $P<0.05$.

to all other groups at all time-points investigated (Fig. 2d).

\section{Human DPSCs proliferation and viability}

The WST-1 proliferation assay was used to determine the indirect effects (i.e. drug(s) release) of antibioticcontaining scaffolds on hDPSCs proliferation. In brief, the colorimetric-based WST-1 assay makes use of a tetrazolium salt that generates a very water-soluble formazan upon cellular reduction (Tominaga et al. 1999). The results of the assay revealed a significant $(P<0.05)$ decrease in proliferation for all groups exposed to CIP-containing scaffolds (Fig. 3) at all timepoints, in a concentration-dependent manner. In contrast, groups exposed to MET and pure PDS showed no change in proliferation. In this study, LIVE/DEAD ${ }^{\circledR}$ assay was performed specifically to qualitatively evaluate cell morphology and viability after 3 days of scaffold exposure. Analysis of hDPSC viability by fluorescence microscopy revealed important differences amongst the groups. Cells exposed to either pure PDS or MET displayed a spindle-shaped fibroblastic cell body with mainly long cellular processes, with strong substrate attachment and associated multiple proliferating cells (Fig. 4a-b). A visual decrease in cell number with a higher \% of dead cells, indicated by the colour red, was observed after exposure to CIP-containing scaffolds. In addition, these cells showed a rounded form without cytoplasmic branched projections (Fig. 4c-f). No cells were seen after 3 days of exposure to the DAP-mimic solution (data not shown).

\section{Discussion}

Selection of the best method for eradication of root canal infection prior to regenerative endodontic procedures should be dictated by two major outcomes, that is the maximization of the antibacterial efficiency whilst preserving the proliferation/differentiation potential of pulp stem cells (Trevino et al. 2011, Martin et al. 2014). Over the past few years, a myriad of studies has been performed (Bottino et al. 2013a, 2014, Palasuk et al. 2014, Waeiss et al. 2014) focusing on the synthesis of antibiotic-containing scaffolds based on the central hypothesis that controlling the release rate of significantly lower (compared to the double and triple antibiotic pastes), yet effective, antibiotic doses might lead to enhanced human dental pulp stem cell viability (hDPSC), whilst preserving antimicrobial activity.

The drug-release data indicated that after an initial burst release (i.e. within the first $24 \mathrm{~h}$ ), a continued maintenance of the $\operatorname{drug}(\mathrm{s})$ concentration for all time-points was observed, suggesting a sustained level of drugs that might be effective in the eradication of existing infection. In fact, a recent study (Palasuk et al. 2014) revealed significant antimicrobial activity of these novel antibiotic-containing electrospun scaffolds over a 14-day period for different bacteria, comparable to activity provided by $0.12 \%$ chlorhexidine. Notably, the percentage of CIP was higher for $1: 3 \mathrm{MET} / \mathrm{CIP}$ scaffolds when compared to those containing CIP only. This observation could be explained by pharmacokinetic interactions of both drugs. Solubility of MET is inversely proportional to $\mathrm{pH}$, with the lowest solubility at about $\mathrm{pH} 8.0$ (Rediguieri et al. 2011), whereas the solubility of CIP, a zwitterionic molecule, is optimal at neutral $\mathrm{pH}$ (Breda et al. 2009). Thus, MET presence in $1: 3 \mathrm{MET} /$ CIP could facilitate the release of CIP from the scaffolds due to physicochemical interactions. The important differences (i.e. a sizeable standard deviation) in mean fibre diameter amongst the antibioticcontaining groups might also play an important role in drug-release kinetics. Full optimization of the various electrospinning conditions, such as voltage and distance tip-collector, amongst others, will be explored in a future investigation to reduce the fibre diameter variability normally associated with electrospinning.

The long-term goal of this research is to translate into clinical practice a two-step tissue engineeringbased strategy for regenerative endodontics by first 

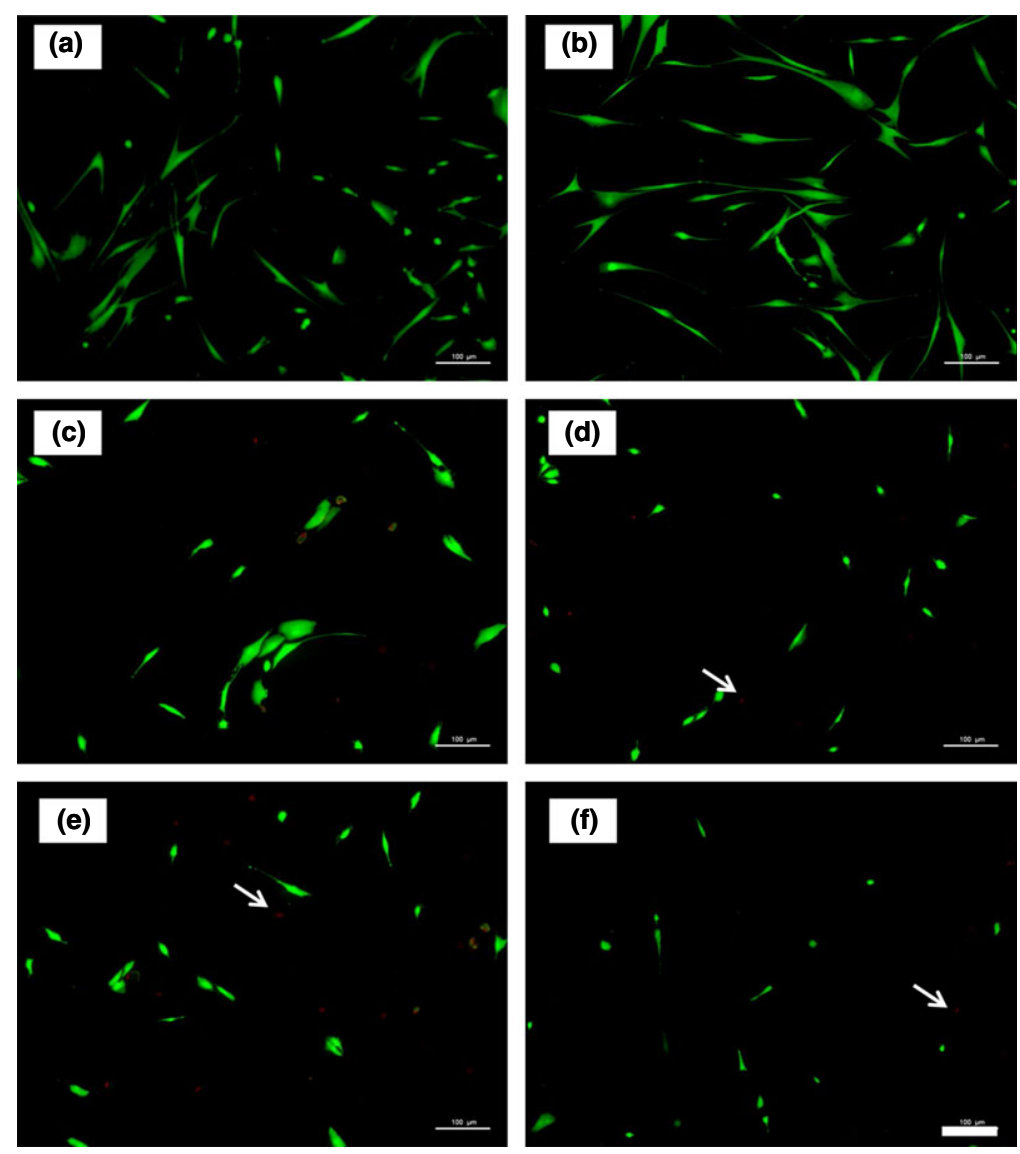

Figure 4 (a-f) Representative fluorescence microscopy images $(25 \times$ magnification, scale bar $=100 \mu \mathrm{m})$ show hDPSCs viability assessed with LIVE/DEAD ${ }^{\circledR}$ assay after exposure to scaffolds for 3 days: (a) Pure PDS; (b) MET; (c) 3 : 1MET/CIP; (d) $1: 1 \mathrm{MET} / \mathrm{CIP}$; (e) $1: 3 \mathrm{MET} / \mathrm{CIP}$ and (f) CIP. Cellular bodies stained green show viable cells. Arrows indicate red stained ethidium bromide-positive nuclei (dead cells).

establishing a bacteria-free environment conducive to tissue regeneration (Step 1) through the use of antibiotic-containing scaffolds, followed by placement of a scaffold encapsulated with growth factors and/or stem cells (Step 2) to drive regeneration of the pulp-dentine complex (Albuquerque et al. 2014). Data from previous studies demonstrated convincing evidence of the antibacterial efficacy of PDS-based antibioticcontaining scaffolds (e.g. vancomycin, rifampicin, metronidazole, ciprofloxacin) against osteomyelitis-, periodontitis-, and root canal infection-associated pathogens (Bottino et al. 2013a, 2014, Palasuk et al. 2014, Waeiss et al. 2014). Here, novel antibiotic-containing scaffolds were evaluated in terms of their potential toxic effects to hDPSC using both proliferation and viability assays. Based on the data presented, the hypothesis was accepted, as the antibiotic-containing scaffolds promoted significantly lower cytotoxic effects when compared to the clinically advocated double antibiotic paste (DAP).

Calcium hydroxide $\left[\mathrm{Ca}\left(\mathrm{OH}_{2}\right)\right]$ is considered to be an excellent antimicrobial medication in endodontics, but its effectiveness can be limited to the main root canal with inadequate dentine penetration (Haapasalo \& Ørstavik 1987, Ercan et al. 2006), mostly due to low solubility and buffering dentine characteristics (Haapasalo et al. 2000, Portenier et al. 2001). Recently, antibiotic-containing pastes (i.e. TAP and DAP), at clinically advocated concentrations, have been shown to significantly affect the proliferation and survival of dental pulp cells (Chuensombat et al. 2013) as well as stem cells from the apical papilla (Ruparel et al. 2012). The present study confirms the highly toxic effects of DAP through the proliferation and viability 
assays after hDPSC exposure to the DAP-mimic, MET/ CIP saturated solution.

From a clinical perspective, antimicrobials may act unfavourably on dental stem cells via two main mechanisms, that is diffusion to apical papilla during time of introduction into the root canal system, and/or by interference of residual drugs with migrating stem cells into the preformed blood clot. Of the two drug components in DAP, no change in either proliferation or viability of MET-only containing scaffolds was noticed. Even though there are studies indicating MET as being responsible for dose-dependent cytotoxic effects both in vitro (Kapoor et al. 1999) and in vivo (Chatzkel \& Vossough 2010, Kuriyama et al. 2011), it has demonstrated favouring eukaryotic cell viability. MET has been shown to increase lymphocyte proliferation (Elizondo et al. 1994); however, the mechanism is not well understood. One plausible explanation is that MET can modulate proliferation through the release of inflammatory cytokines as observed in human periodontal ligament cells (Rizzo et al. 2010). Thus, MET, despite its proven antimicrobial characteristics, could also be considered to be a potential stem cell proliferation inducer when delivered locally using scaffolds to eliminate root canal infection. Regarding CIP, an inhibitory effect of all CIP-containing polymer scaffolds on both proliferation and viability of hDPSCs was observed. Dose-dependent cytotoxic effects of antibiotics from the fluoroquinolones group, including CIP, were described elsewhere (Sobolewska et al. 2013). Lastly, an important decrease in hDPSC viability for all samples exposed to CIP with a dosedependent trend, where the least toxicity was seen in cells exposed to scaffolds with the lowest CIP content (3:1 MET/CIP). Future studies will focus on the determination of an optimal concentration of CIP with minimal or no toxic effects to stem cells, whilst still maintaining antimicrobial efficacy. In a clinical setting, the lowest possible CIP concentration within scaffolds with modulatory effects of MET might lead to improvement in the survival, proliferation and regenerative capacity of dental pulp stem cells.

\section{Conclusion}

Synthesized antibiotic-containing scaffolds had significantly lower effects on hDPSCs' proliferation and viability when compared to the saturated CIP/MET solution (DAP).

\section{Acknowledgements}

This work was supported in part by start-up funds from the IU School of Dentistry and the NIH-NIDCR (Grant \# DE023552) (all to M.C.B.). The authors are grateful to Dr. Angela Bruzzaniti for access to fluorescent microscope and to Dr. Pierre Eleniste for his invaluable suggestions during fluorescent imaging.

\section{Conflict of interests}

The authors declare no conflict of interests.

\section{References}

Albuquerque MT, Valera MC, Nakashima M, Nör JE, Bottino MC (2014) Tissue-engineering-based Strategies for Regenerative Endodontics. Journal of Dental Research 93, 122231.

Allam E, Zhang W, Al-Shibani N et al. (2011) Effects of cigarette smoke condensate on oral squamous cell carcinoma cells. Archives of Oral Biology 56, 1154-61.

Andreasen FM, Andreasen JO, Bayer T (1989) Prognosis of root-fractured permanent incisors-prediction of healing modalities. Endodontics and Dental Traumatology 5, 11-22.

Andreasen JO, Farik B, Munksgaard EC (2002) Long-term calcium hydroxide as a root canal dressing may increase risk of root fracture. Dental Traumatology 18, 134-7.

Banchs F, Trope M (2004) Revascularization of immature permanent teeth with apical periodontitis: new treatment protocol? Journal of Endodontics 30, 196-200.

Berkhoff JA, Chen PB, Teixeira FB, Diogenes A (2014) Evaluation of triple antibiotic paste removal by different irrigation procedures. Journal of Endodontics 40, 1172-7.

Bottino MC, Thomas V, Janowski GM (2011) A novel spatially designed and functionally graded electrospun membrane for periodontal regeneration. Acta Biomaterialia 7, 216-24.

Bottino MC, Kamocki K, Yassen GH et al. (2013a) Bioactive nanofibrous scaffolds for regenerative endodontics. Journal of Dental Research 92, 963-9.

Bottino MC, Yassen G, Platt J et al. (2013b) A novel threedimensional scaffold for regenerative endodontics:materials and biological characterizations. Journal of Tissue Engineering Regenerative Medicine. doi: 10.1002/term.1712. [Epub ahead of print].

Bottino MC, Arthur RA, Waeiss RA, Kamocki K, Gregson KS, Gregory RL (2014) Biodegradable nanofibrous drug delivery systems: effects of metronidazole and ciprofloxacin on periodontopathogens and commensal oral bacteria. Clinical Oral Investigations 18, 2151-8.

Breda SA, Jimenez-Kairuz AF, Manzo RH, Olivera ME (2009) Solubility behavior and biopharmaceutical classification of 
novel high-solubility ciprofloxacin and norfloxacin pharmaceutical derivatives. International Journal of Pharmaceutics 371, 106-13.

Chatzkel JA, Vossough A (2010) Metronidazole-induced cerebellar toxicity. Pediatric Radiology 40, 1453.

Chuensombat S, Khemaleelakul S, Chattipakorn S, Srisuwan $\mathrm{T}$ (2013) Cytotoxic effects and antibacterial efficacy of a 3-antibiotic combination: an in vitro study. Journal of Endodontics 39, 813-9.

Diogenes AR, Ruparel NB, Teixeira FB, Hargreaves KM (2014) Translational science in disinfection for regenerative endodontics. Journal of Endodontics $\mathbf{4 0}$ (4 Suppl), S52-7.

Elizondo G, Montero R, Herrera JE, Hong E, Ostrosky-Wegman P (1994) Lymphocyte proliferation kinetics and sister-chromatid exchanges in individuals treated with metronidazole. Mutation Research 305, 133-7.

Ercan E, Dalli M, Dulgergil CT (2006) In vitro assessment of the effectiveness of chlorhexidine gel and calcium hydroxide paste with chlorhexidine against Enterococcus faecalis and Candida albicans. Oral Surgery, Oral Medicine, Oral Pathology, Oral Radiology, and Endodontics 102, e27-31.

Geisler TM (2012) Clinical considerations for regenerative endodontic procedures. Dental Clinics of North America 56, 603-26.

Haapasalo M, Ørstavik D (1987) In vitro infection and disinfection of dentinal tubules. Journal of Dental Research 66, 1375-9.

Haapasalo HK, Siren EK, Waltimo TM, Ørstavik D, Haapasalo MP (2000) Inactivation of local root canal medicaments by dentine: an in vitro study. International Endodontic Journal 33, 126-31.

Hoshino E, Kurihara-Ando N, Sato I et al. (1996) In-vitro antibacterial susceptibility of bacteria taken from infected root dentine to a mixture of ciprofloxacin, metronidazole and minocycline. International Endodontics Journal 29, 125-30.

Kapoor K, Chandra M, Nag D, Paliwal JK, Gupta RC, Saxena RC (1999) Evaluation of metronidazole toxicity: a prospective study. International Journal of Clinical Pharmacology Research 19, 83-8.

Kim JH, Kim Y, Shin SJ, Park JW, Jung IY (2010) Tooth discoloration of immature permanent incisor associated with triple antibiotic therapy: a case report. Journal of Endodontics 36, 1086-91.

Kim BS, Park KE, Park WH, Lee J (2013) Fabrication of nanofibrous scaffold using a PLA and hagfish thread keratin composite; its effect on cell adherence, growth, and osteoblast differentiation. Biomedical Materials 8, 045006. doi: 10.1088/1748-6041/8/4/045006. Epub 2013 Jun 4.

Kuriyama A, Jackson JL, Doi A, Kamiya T (2011) Metronidazole-induced central nervous system toxicity: a systematic review. Clinical Neuropharmacology 34, 241-7.

Lin LM, Ricucci D, Huang GT (2013) Regeneration of the dentine-pulp complex with revitalization/revascularization therapy: challenges and hopes. International Endodontics Journal 47, 713-24.

Lovelace TW, Henry MA, Hargreaves KM, Diogenes A (2011) Evaluation of the delivery of mesenchymal stem cells into the root canal space of necrotic immature teeth after clinical regenerative endodontic procedure. Journal of Endodontics 37, 133-8.

Martin DE, De Almeida JF, Henry MA et al. (2014) Concentration-dependent effect of sodium hypochlorite on stem cells of apical papilla survival and differentiation. Journal of Endodontics 40, 51-5.

Moazami F, Sahebi S, Jamshidi D, Alavi A (2014) The longterm effect of calcium hydroxide, calcium-enriched mixture cement and mineral trioxide aggregate on dentin strength. Iranian Endodontic Journal 9, 185-9.

Murray PE, Garcia-Godoy F, Hargreaves KM (2007) Regenerative endodontics: a review of current status and a call for action. Journal of Endodontics 33, 377-90.

Palasuk J, Kamocki K, Hippenmeyer L et al. (2014) Bimix Antimicrobial Scaffolds for Regenerative Endodontics. Journal of Endodontics 40, 1879-84.

Petrino JA, Boda KK, Shambarger S, Bowles WR, McClanahan SB (2010) Challenges in regenerative endodontics: a case series. Journal of Endodontics 36, 536-41.

Portenier I, Haapasalo H, Rye A, Waltimo T, Ørstavik D, Haapasalo M (2001) Inactivation of root canal medicaments by dentine, hydroxylapatite and bovine serum albumin. International Endodontic Journal 34, 184-8.

Rediguieri CF, Porta V, G Nunes DS et al. (2011) Biowaiver monographs for immediate release solid oral dosage forms: metronidazole. Journal of Pharmaceutical Sciences 100, 1618-27.

Ribeiro FC, Souza-Gabriel AE, Marchesan MA, Alfredo E, Silva-Sousa YT, Sousa-Neto MD (2008) Influence of different endodontic filling materials on root fracture susceptibility. Journal of Dentistry 36, 69-73.

Rizzo A, Paolillo R, Guida L, Annunziata M, Bevilacqua N, Tufano MA (2010) Effect of metronidazole and modulation of cytokine production on human periodontal ligament cells. International Immunopharmacology 10, 744-50.

Ruparel NB, Teixeira FB, Ferraz CC, Diogenes A (2012) Direct effect of intracanal medicaments on survival of stem cells of the apical papilla. Journal of Endodontics 38, 1372-5.

Sabrah AH, Yassen GH, Gregory RL (2013) Effectiveness of antibiotic medicaments against biofilm formation of Enterococcus faecalis and Porphyromonas gingivalis. Journal of Endodontics 39, 1385-9.

Sahebi S, Moazami F, Abbott P (2010) The effects of shortterm calcium hydroxide application on the strength of dentine. Dental Traumatology 26, 43-6.

Sato I, Ando-Kurihara N, Kota K, Iwaku M, Hoshino E (1996) Sterilization of infected root-canal dentine by topical application of a mixture of ciprofloxacin, metronidazole and minocycline in situ. International Endodontic Journal 29, $118-24$. 
Simon S, Smith AJ (2014) Regenerative endodontics. British Dental Journal 216, E13. doi:10.1038/sj.bdj.2014.243.

Sobolewska B, Hofmann J, Spitzer MS, Bartz-Schmidt KU, Szurman P, Yoeruek E (2013) Antiproliferative and cytotoxic properties of moxifloxacin on rat retinal ganglion cells. Current Eye Research 38, 662-9.

Tominaga H, Ishiyama M, Ohseto F et al. (1999) A watersoluble tetrazolium salt useful for colorimetric cell viability assay. Analytical Communications 36, 47-50.

Trevino EG, Patwardhan AN, Henry MA et al. (2011) Effect of irrigants on the survival of human stem cells of the apical papilla in a platelet-rich plasma scaffold in human root tips. Journal of Endodontics 37, 1109-15.
Waeiss RA, Negrini TC, Arthur RA, Bottino MC (2014) Antimicrobial Effects of Drug-Containing Electrospun Matrices on Osteomyelitis-Associated Pathogens. Journal of Oral Maxillofacial Surgery 72, 1310-9.

Yadlapati M, Souza LC, Dorn S, Garlet GP, Letra A, Silva RM (2014) Deleterious effect of triple antibiotic paste on human periodontal ligament fibroblasts. International Endodontic Journal 47, 769-75.

Yassen GH, Vail MM, Chu TG, Platt JA (2013) The effect of medicaments used in endodontic regeneration on root fracture and microhardness of radicular dentine. International Endodontic Journal 46, 688-95. 